\title{
Becoming-Music in 4 Minutes and 33 Seconds
}

\author{
Dorothea Hines \\ Trent University, Peterborough, Canada
}

\begin{abstract}
In accordance to Langerian aesthetic theory, Mark Campbell (1992) concludes that Cage's 4'33” (1952) is by no means aesthetic music. I argue the antithesis: Cage's 4'33” satisfies Langerian aesthetic theory, and is indeed "aesthetic" music. Cage does something more: he satisfies Langerian aesthetic theory, yet he is not limited by it. He does not simply create music, nor does he offer listeners a musical space. He creates what Gilles Deleuze and Félix Guattari (1987) call a line of becoming that passes between music making and a musical space. In 4 minutes and 33 seconds of silence, Cage presents a sense of emptiness and numbness felt simultaneously with fullness and explosion. In what appears to be stillness, the listener experiences the flux of movement; what appears to be devoid of depth, is filled with complexities. 4'33" embraces chance, uncertainty, and the unknown; it is an experimental process; it is becoming-music in 4 minutes and 33 seconds.
\end{abstract}

Keywords: John Cage, Langerian aesthetic theory, Gilles Deleuze, Félix Guattari, line of becoming, music ontology

\section{Silence}

John Cage presents 4 minutes and 33 seconds of silence in his work 4'33” (1952). He presents a momentary sense of emptiness and numbness simultaneously felt with fullness and explosion; he presents what I believe Gilles Deleuze and Félix Guattari (1987) call a line of becoming that passes between music making and a musical space. I write this paper in response to Mark Campbell's John Cage's 4'33": Using Aesthetic Theory to Understand a Musical Notion (1992). Appling 4'33” to Langerian aesthetic theory, Campbell concludes that Cage's work is by no means (aesthetic) music:

In 4'33" Cage presents us with an "empty” art form and asks us to experience its emptiness. With a pianist sitting at a keyboard doing nothing for four minutes and thirty-three seconds, we can hardly say that we are experiencing the tonal analogue of emotive life, or the logic of expression in musical form, or a sense of sonorous transience with the plasticity of space, or growth, or "listening" - in any real or imagined sense. Nor can we say that 4'33" is, in the normative way, a complex event; nor does it seem to possess auditory movement, nor elements that characterize constituency within wholeness, nor kinesis, nor much process (if any). (Campbell, 1992, pp. 89-90)

I would like to offer another perspective. In this paper, I argue that Cage's 4'33” is indeed music; music that not only satisfies aesthetic theory (which Campbell prematurely uses to measure the quality of "good" music), but also acts as a line of becoming that does not merely make music nor offers a musical space, but passes between making music and a musical space. 4'33" presents silence as a manifestation of movement; it is becoming-music in 4 minutes and 33 seconds.

Dorothea Hines, M.A. Candidate, Trent University. 


\section{Musical Space vs. Making Music}

I have mentioned a few concepts that need to be explained further if we are to fully understand Cage's 4'33” as a line of becoming. Michael Szekely presents ontology of musical creation and performance in Becoming-Still: Perspectives on Musical Ontology After Deleuze and Guattari (2003) in which he analyses Deleuze and Guattari's concept of the schizoid musician as, using his words, “one who has the ability to apprehend that of a musical space” (1987, p. 113). The term musical space is a bit misleading. Musical space may be marked by a physical space but it is not limited by physical space. As Szekely explains,

Musical space is better initially apprehended as a kind of fluid paradigm rather than as a totality. With all the technical implements, imaginative intuitions, and methodological strategies, the performer is situated within the musical space. There is not yet any ambition, any intention, here—only as a yet open territory of possibility. (2003, p. 114)

The performer or musician or audience members are not simply there nor here; they both inhabit and embody a musical space. In contrast, Szekely describes the musician who makes music as one who

...is riddled with fear, preoccupied with intention, consumed with context. It, [the "I" subject,] must, in turn, either psychologize itself into a motivation toward aesthetic value structures or become dissolved, albeit with discontinuous agitations, into a smooth surface- that is, releasing into, surrendering to, being seduced by the moment of the musical space. (2003, p. 114)

Cage does not simply make music with 4'33”; he is not preoccupied with or motivated by a preexisting aesthetic structure, but creates a musical space in which the audience embodies music and the musical process.

Campbell would not agree with this statement; he is absorbed with making music and an existing musical aesthetic that defines what valuable and beautiful music is. He relies upon the Langerian perspective when describing music and the musical experience. Susanne Langer believes that music is analogous to the life of feeling (1992, p. 83). Langer incorporates three axioms in her definition of aesthetic music:

(1) music makes perceptible in form what we experience in human feeling;

(2) music's meaning or import is nondiscursive and presentational; and

(3) music is a symbol, but its characteristic function is not self-expression but logical expression. (1992, p. 83)

To summarize, Campbell states,

....as an expressive form, music exists as a resemblance of the nature of feeling. Feeling, as [Langer] uses the word, is much more comprehensive in concept than emotion and includes the entire range of our conscious awareness as living, breathing, virtual organisms. Music does not symbolize an individual feeling but accounts for an awareness of how feelings “go". (1992, p. 84)

Campbell argues that Cage's 4'33” is emotionally and intellectually disengaging; it lacks human emotion and awareness of human feeling: "the silence is distancing, not deeper confrontation or disinterested inquiry, but...the absence of articulate growth” (1992, p. 90). I expect this response from someone who focuses on making music. Campbell fixates on an end goal that is predetermined by Langer's aesthetic structure. He does not listen, in an active sense, but projects this aesthetic structure into Cage's silence; he projects preconceived notions of making music onto 4'33". As a result, he listens for making music, and thus completely misses what can be heard in Cage's musical space. Campbell does not see that 4'33” satisfies all three Langerian qualities of musical aesthetics:

(1) music makes perceptible in form what we experience in human feeling. 4'33” does not provide a 
representation of human feeling as making music does, but creates a space where we literally experience (our) human feelings;

(2) music's meaning or import is nondiscursive and presentational. It would be easy to call 4'33" discursive, monotonous, or dull...emphasizing the mundane can produce this effect. Cage's presentation of the monotonous mundane is, however, spontaneous, it is left up to chance, and is an active creative force from which we draw meaning in relation to our individual experience. And finally,

(3) music is a symbol, but its characteristic function is not self-expression but logical expression. Although 4'33" creates a musical space that can house self-expression, it does possess logical expression in the form of a score: a complete score broken up into three sections, separated by tacets, accompanied by a description written by Cage himself (see Appendix A):

NOTE: The title of this work is the total length in minutes and seconds of its performance. At Woodstock, N.Y., August 29, 1952, the title was 4'33' and the three parts were 33', 2'40', and 1'20'. It was performed by David Tudor, pianist, who indicated the beginnings of the parts by closing, the endings by opening, the keyboard lid. However, the work may be performed by any instrumentalist or combination of instrumentalists and last any length of time. (1952)

The three tacets provide structure for logical expression. It is within these tacets, however, that Cage expands upon the three Langerian qualities. He creates a musical space filled with chance and spontaneity by calling our attention to the mundane. Just as a musical space can embrace a physical space but is not limited by it, 4'33" embraces musical aesthetics but is not limited by them.

Campbell further describes 4'33":

We have limited opportunity for exercising our powers of perception, discrimination, characterization, conception, organization, reflection, or contemplation. We wait in all too conscious silence. We are confused, because the experience and the object are deficient. Our mind suggests to make sense of 4'33”. Is it music? Is it a musical experience? To answer our two questions, let us sum what the work is and its experience. There seems to be no clear organization of the expressive import of music, not any significant form, or logical construction. There is a lack of wholeness, completeness, unity. There seems to be no development, no unfolding, no variety, no use of the sonorous or the formal elements of music, no articulate movement. There is a lack of complexity. There is no content. There seems to be no commanding form, no process. (1992, p. 90)

First, recalling Cage's score, 4'33" does in fact possess a clear form of logical construction. Furthermore, Szekely believes that the score is not sufficient to fully experience music: the score tries to

...negotiate the balance between the real and the virtual, the sound and the image, the action and the symbol. We forget that a musical space strikes us as already virtual reality, as sound-image, as symbolic action. So, instead, we might ask the question, how after all goes a score? We discover this only by playing it. A score is not a way to 'create' a musical space. Playing a score is a musical space. (2003, p. 119)

A score itself cannot constitute a musical space; it is in the act of playing a score that creates one, composing it and reading it and listening to it and playing it. In addition, Szekely observes, "simply apprehending a score implies an arborescence—a rooting, a grounding, of music in that score. A musical space however, implies a nomadism-an openness, an explosion, of playing” (1992, p. 119). Musical space is open to possibility; it suspends limits of making music and embraces spontaneity. Unlike previous scores and compositions, Cage does not present a resemblance of human qualities, their states of mind, their activities; he presents them quite literally. He creates a space in which the listener can experience life and its full feeling. Through no aesthetic comes aesthetic; through mundane "noise" comes a complete musical experience. It is 
through Cage's presentation of emptiness that one experiences wholeness, completeness, and unity; with no development comes development; with no variety comes variety; by presenting stillness the listener experiences the flux of moment; the lack of sonorous and formal musical elements fills the space with them; it is a simple score that appears to be devoid, however, this simple score is filled with complexities, and if the listener takes the time to listen to its complexities, he will find ample content. 4'33" takes the form of experimental process; it embraces chance, uncertainty, and the unknown.

The opportunity to exercise our powers of perception, discrimination, characterization, conception, organization, reflection, or contemplation is not handed to us in 4'33", as Campbell thinks it ought to be; and this lack of hit-you-over-the-head obviousness does not mean it lacks opportunity. On the contrary, we must find opportunity with our full attention, with our full conscious awareness of what is, and what has always been. We must work for it; and in utilizing our ears to first find opportunities, we exercise more rigorously our abilities whether that is perception, discrimination, characterization, conception, organization, reflection, or contemplation.

\section{A Line of Becoming: Connecting Musical Space and Making Music}

I have thus far argued that Cage creates a musical space through 4'33". I admit that this is a simple conclusion, a dualistic conclusion that holds 4'33" as a musical space in opposition to making music. Let us listen to Deleuze and Guattari to complicate this conclusion. 4'33" may be a musical space, but it should not be limited to a musical space. I argue that 4'33" is what Deleuze and Guattari call a line of becoming that passes between a musical space and making music.

In their dual authored book, A Thousand Plateaus (1987), Deleuze and Guattari explain what they call $a$ line of becoming:

.... line of becoming is not defined by points that it connects, or by points that compose it; on the contrary, it passes between points, it comes up through the middle, it runs perpendicular to the points first perceived, transversally to the localizable relation to distant or contiguous points. A point is always a point of origin. But a line of becoming has neither beginning nor end, departure nor arrival, origin nor destination. (p. 293)

As a line of becoming, Cage's 4'33" is not limited to a point, an origin, a destination; it is not limited to the score, the tacets, a single instrument, or a combinations of instruments; it is not limited to making-music, or a musical space, but passes between them. As Deleuze and Guattari argue, becoming is an in-between state: "a becoming is neither one nor two, nor the relation of the two; it is the in-between, the border or line of flight or descent running perpendicular to both” (1987, p. 293). In other words, a line of becoming not only divides but also unifies; it creates a possibility in which two points can coexist, as what Deleuze and Guattari call a block. A block

...constitutes a zone of proximity and indiscernibility, a no-man's land, a nonlocalizable relation sweeping up the two distant or contiguous points, carrying one into the proximity of the other-and the border-proximity is indifferent to both contiguity and to distance. (Deleuze \& Guattari, 1987, p. 293)

Two asymmetrical movements or points coexist and combine forming a block. Making music and a musical space constitute two asymmetrical movements that are combined in 4'33", which acts as a block of becoming, becoming-music.

According to Deleuze and Guattari, the problem with music is its refrain (1987, p. 301). As a line of 
becoming, becoming-music treats the refrain as transversal; it connects making-music and a musical space. In doing so, becoming-music uproots, or (using Deleuze and Guattari’s words) deterritorializes the refrain:

...music submits the refrain to this very special treatment of the diagonal or transversal, it uproots the refrain from its territoriality. Music is creative, active operation that consists in deterritorializing the refrain. Whereas the refrain is essentially territorial, territorializing, or reterritorializing, music makes it a deterritorialized content for a deterritorializing form of expression. (1987, p. 300)

Becoming-music is a creative, active, and spontaneous force that upsets the musical accompaniment for a refrain. The Langerian aesthetic qualities, which I believe are forms of refrains that Campbell projects onto 4'33", remain unsatisfied because 4'33' uproots them, challenges them, renders them unsettled. Campbell asks, what are the aesthetic qualities of 4'33"? I suggest a new question: what limits do these aesthetic qualities impose on 4'33", and what would happen if we ignored them? Uprooted them? Deterritorialized them?

This is not to say that the refrain has no place in becoming-music, for it is in the act of deterritorializing the refrain that we experience becoming-music. Just as two points coexist with a block, the refrain, although altered, coexists with becoming-music. Deleuze and Guattari elaborate:

...the motif of refrain may be anxiety, fear, joy, love, work, walking, territory...but the refrain itself is the context of music. We are not at all saying that the refrain is the origin of music, or that music begins with it. It is not really known when music begins. The refrain is rather a means of preventing music, warding it off, or forgoing it. But music exists because the refrain exists also, because music takes up the refrain, lays hold of it as a content in a form of expression, because it forms a block with it in order to take it somewhere else. (1987, p. 300)

We see here that a line of becoming connects the refrain and becoming-music. It is not becoming-music versus the refrain, but becoming-music in relation to the refrain. If we look at 4'33" as a line of becoming, it becomes an in-between state, a state that passes through making music and a musical space. We enter into this space only to realize it has been present the entire time. This realization only comes, however, when we engage with unaltered awareness, when we listen to what can be heard instead of projecting what we think we should hear. The score, moreover, can never be performed twice; each time it is played, ephemeral and contextual (mundane) sounds (noise) fill the space that can never be replicated or imitated. The spontaneity of the work is an active force that both fills and empties the space. The refrain is thus deterritorialized; 4'33” does not simply fill the space with music, but simultaneously empties it. It is within this flux of simultaneous filling and empting that we experience becoming-music.

Returning to 4'33"'s inimitable quality: becoming-music is not a result of imitation. Deleuze and Guattari argue,

...one does not imitate; one constitutes a block of becoming. Imitation enters in only as an adjustment of the block, like a finishing touch, a wink, a signature. But everything of importance happens elsewhere: in the becoming-spider of the dance, which occurs on the condition that the spider itself becomes sound and color, orchestra and painting. (1987, p. 305)

Again, we see here that becoming is not in opposition to imitation, it is not dualistic nor embraces dichotomy; there are aspects of imitation that exist in becoming-music (imitation can be used to adjust the block). Campbell, however, listens solely for imitation; an imitation of aesthetic qualities that he believes should exist in music. He, therefore, focuses on what he does not hear (or what he believes he should hear), and not what can be heard. As a result, Campbell concludes that 4'33" is noise, and thus not music. Is everything that is not noise music? Deleuze and Guattari argue that one cannot define music by comparing it to noise. 
They assert, "the difference between noise and sound is definitely not a basis for a definition of music, or even for the distinction between musician birds and nonmusician birds. Rather, it is the labor of the refrain” (1987, p. 302); it is the way in which music "lays hold of the refrain, makes it more and more sober, reduced to a few notes, then takes it down a creative that is so much richer, no origin or end of which is in sight...” (1987, p. 302). It is in the act (or labour) of deterritorializing the refrain that we unlock the creative and spontaneous force of becoming-music.

It would be easy to call becoming-music chaos; it uproots the refrain, and lacks traditional aesthetic qualities and structure. Deleuze and Guattari argue, however, that "forces of chaos, terrestrial forces, cosmic forces: all of these confront each other and converge in the territorial refrain” (1987, p. 312). Cosmic forces, terrestrial forces, forces of chaos are not subjects to the refrain's limitations; they create their own block, a transversal and complex space where, what Deleuze and Guattari call, a chaosmos exists. Chaosmos is a line of becoming, and it is within the chaosmos that rhythms are born:

...what chaos and rhythm have in common is the in-between-between two milieus, rhythm-chaos of the chaosmos: "Between night and day, between that which is constructed and that which grows naturally, between mutations from the inorganic to the organic, from plant to animal, from animal to humankind, yet without this series constituting a progression...” In this in-between, chaos becomes rhythm. (1987, p. 313)

I have no doubt that, in addition to musical aesthetics, Campbell would eagerly state that 4'33" possess no rhythm. I argue that 4'33” does indeed possess rhythm within its chaos, within the spontaneous mundane, unnoticed noise, within the coughing, sneezing, sighing, and awkward chair shifting. Cage presents rhythmic chaos. He deterritorializes the refrain of musical aesthetics in the form of silence. He presents his concerto as an assemblage of chaos (chaos, I add, that preexists any of Cage's efforts), which becomes rhythm as it passes through making music and a musical space. As I believe Deleuze and Guattari would argue, Cage has performed a labour, a labour that resulted in a deterritorialized refrain of music released into the Cosmos. I guess all that is left to do is to listen...embody silence...in 4 minutes and 33 seconds.

\section{References}

Cage, J. (1952). 4’33. Performance. 4:33 minutes.

Campbell, M. R. (1992). John Cage's 4'33”: Using aesthetic theory to understand a musical notion. Journal of Aesthetic Education, 26(1), 83-91.

Deleuze, G., \& Guattari, F. (1987). A thousand plateaus: Capitalism and schizophrenia. Minneapolis: University of Minnesota Press.

Szekely, M. (2003). “Becoming-Still: Perspectives on Musical Ontology after Deleuze and Guattari.” Social Semiotics, 13(2), 113-128. 


\section{Appendix A}

\section{I}

TACFT

II

TACFT

III

TACET

NOTE; The title of this rork 13 the total length in minutes and seconds of its performance. At Foods tocle, N.Y., August 29, 195?,

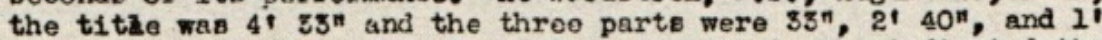
20". It was por?orned by David Tudor, planist, viso indicated the beginnings of parts by closing, the ondincs by opening, tire koyboard lid. Horrover, the work aay bo performed $b_{j}$ and instrumentalist or combinntion of Instrumenteliets and last any loneti of time.

FOR IFWIN KRPAIEN

JOI: CAGE

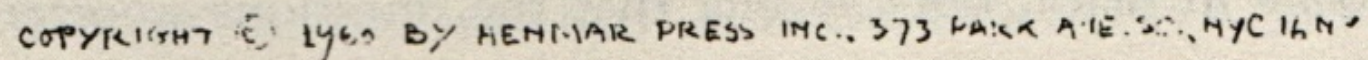

